\title{
EL ESPIONAJE HISPÁNICO DESPUÉS DE LEPANTO: EL PROYECTO DE FRAY DIEGO DE MALLORCA ${ }^{1}$
}

\section{The Hispanic Intelligence after Lepanto: Fray Diego de Mallorca's plan}

Gennaro VARRIALE

Università degli Studi di Genova

Correo-e: g.varriale@live.com

RESUMEN: En primer lugar, el artículo analiza la red de espías que opera dentro de Estambul durante la época de Felipe II, presentando bajo una nueva luz la conocida «Conjura de los Renegados», organizada al margen de la derrota hispánica en la isla de Yerba. Mientras, la segunda parte está dedicada a los proyectos surgidos después de los últimos choques entre los dos grandes imperios del Mediterráneo. En particular la atención está centrada en el grupo de agentes aglutinados en torno al franciscano Diego de Mallorca.

Palabras clave: Mediterráneo; Imperio Otomano; Monarquía Hispánica; espionaje; cautivos.

ABSTRACT: Firstly, the essay focuses on the intelligence during Philip II's age in Istanbul, showing new clues about the «Renegades' Conspiracy», organized due to the Hispanic defeat in the island of Djerba. Meanwhile, the second part focuses on the projects that emerged after the last clashes between the two empires of the Mediterranean. Mainly the attention is

1. Quiero agradecer a todos los miembros del CEDCS (Centro Europeo de Difusión de las Ciencias Sociales, Alcalá de Henares), particularmente Emilio Sola, Esmeralda de Luis y Gonzalo García Fernández, sin su ayuda y apoyo esta investigación no hubiera sido imposible. 
drawn to the group of secret agents planned by a Franciscan monk called Diego de Mallorca.

Key words: Mediterranean; Ottoman Empire; Hispanic Monarchy; Intelligence; Captives.

El verano de 1560 la flota turco-berberisca hundía las esperanzas de Felipe II en las aguas alrededor de Yerba. Frente a la isla tunecina, el almirante Piali Bajá conseguía una victoria aplastante que permitía a los otomanos llevarse una multitud de esclavos a Constantinopla. Entre los prisioneros había miembros distinguidos de la élite hispánica como Berenguer de Requesens, Álvaro de Sande, Sancho de Leiva y Gastón de la Cerda, hijo del virrey siciliano².

Solucionado al menos momentáneamente el conflicto con los franceses, en 1559 Felipe II asentía por primera vez los afanes de sus hombres en la frontera mediterránea. Realmente, la campaña naval contra Berbería se emprendió por las continuas peticiones que hacían desde Palermo el virrey Medinaceli y desde Malta el Maestre de la Orden, Jean de la Valette. Mientras, el Duque de Alcalá era el único que en el Mediterráneo central defendía una posición diferente, de hecho, el Virrey de Nápoles pedía cautela en la guerra contra el Turco y sus corsarios ${ }^{3}$.

Sin embargo, el rey confió en las razones de Medinaceli. Según el Virrey de Sicilia, Dragut estaba aislado y marginado por los dignitarios turcos. En la corte de Constantinopla la lucha entre las facciones alcanzaba su punto más álgido en la sucesión del sultán. Además, para lanzar un ataque a Poniente, Solimán ahora no podía contar con el tradicional aliado francés, que acababa de firmar la Paz de Cateau Cambrésis ${ }^{4}$ :

Juzgavan que las dichas Galeras yvan a proveer las cosas de Argel haziéndose la paz temiendo [los otomanos] que Su Majestad se resolverá de hazer aquella empresa y quando continuase la guerra se podrán juntar con las de Francia para hazer el daño que pudiesen ${ }^{5}$.

En cambio la armada del sultán abrumó a las tropas encabezadas por Medinaceli: el pánico cundió entre vasallos y partidarios del soberano hispánico. Asimismo, la expedición hacia la costa tunecina había sido el estreno de Felipe II en el escenario mediterráneo, por eso los adversarios del rey se aprovecharon

2. García Arenal, M. y Bunes Ibarra, M. Á.: Los españoles y el Norte de África. Siglos XV-XVIII, Madrid, 1992, p. 89.

3. Archivo General de Simancas [en adelante AGS], Estado, Nápoles, leg. 1050, d. 10. Duque de Alcalá a Felipe II, 10 enero 1560.

4. Le Fur, D: Henri II, París, 2009.

5. AGS, Estado, Sicilia, leg. 1124, d. 184. Avisos enviado por Medinaceli, 19 diciembre 1558. 
del desastre militar para difundir una imagen desconsoladora del Rey Católico, incapaz de seguir el cauce surcado por su padre, Carlos V. La Cristiandad ya no tenía paladín ${ }^{6}$. Después de la victoria otomana, el Maestre de los Hospitalarios escribía una carta aterradora a Su Majestad, en que se esclarecía la jactancia del enemigo cara al porvenir:

Proseguiendo el Turco la feliçidad de los suçesos de este año persuadido de ellos que qualquier cosa se le hará façil haviéndole hecho el General de su Armada muy llano el camino para qualquier obra entiendo que prepara gruesa Armada para el año que viene ${ }^{7}$.

El fracaso de Yerba provocó un cambio en la política naval de la Casa de Austria. Finalmente, Felipe II dejaba apartada la estrategia de sus predecesores. El nuevo objetivo de la dinastía era la constitución de una flota capaz de frenar el avance otomano en el Mediterráneo. Mientras, los presidios africanos perdían valor en la contienda, abandonados o conquistados por los turco-berberiscos ${ }^{8}$. Con unos años de retraso, el soberano aceptaba así los consejos que el cardenal Pedro Pacheco le había dado cuando Felipe era sólo el heredero al trono:

Me pareçe a çerca de las galeras, aquí hay gran aparejo para armar galeras y en cantidad y no a mucha costa, el sustentarlas seria algún trabajo pero mucho más es lo que se gasta cada año por razón desta armada. Vuestra Alteza crea que si Su Majestad tenga çient galeras en orden que el Turco nunca embiaría acá armada ${ }^{9}$.

Muy pronto se hizo patente que la razón principal del desastre hispánico en Berbería había sido la falta de información. El baylo veneciano en Constantinopla se mostraba contundente. Regresado a Venecia en el mismo año de Yerba, Marino Cavalli presentaba al Senado su relación, en la cual las primeras palabras estaban dedicadas a la importancia de las noticias reservadas, indispensables para la acción de cualquier príncipe. A fin de aclarar aún más su convencimiento, el embajador hacía referencia en la sesión del ágora republicano a la imprudencia que Felipe II había mostrado en ordenar la campaña militar ${ }^{10}$ :

E non posso credere che il serenissimo re di Spagna, se avesse avuta vera informazione delle cose turchesche, ovvero avesse creduto a chi glie ne poteva dar buona notizia,

6. Rodríguez Salgado, M. J.: Felipe II, el «Paladín de la Cristianidad» y la paz con el Turco, Valladolid, 2004.

7. AGS, Estado, Sicilia, leg. 1125, d. 129. Gran Maestre a Felipe II, Malta 26 noviembre 1560. 1966.

8. BRAUdel, F.: La Méditerranée et le monde méditerranéen à l'époque de Philippe II, París,

9. AGS, Estado, Nápoles, leg. 1046, d. 37. Cardinal Pacheco al príncipe Felipe, Nápoles 7 marzo 1554.

10. VAlensi, L.: Venise et la sublime porte: la naissance du despote, París, 1987. 
avesse cominciato l'anno passato, e finito il presente, un così inescusabile errore, come ha fatto, con grandissimo detrimento suo ed indegnità della Cristianità tutta ${ }^{11}$.

Ilustres súbditos del Rey Católico compartían la reflexión del baylo, sobre todo los diplomáticos de Felipe II en los territorios italianos. Tras pocos meses del desastre africano, el secretario en Venecia Garci Hernández señalaba al soberano, que la distancia entre la Monarquía Hispánica y la Serenísima era todavía enorme, cuando había necesidad de obtener información rápida y cierta en torno a los otomanos ${ }^{12}$.

La inexistencia de relaciones oficiales entre Madrid y Estambul obligaba a Felipe II a renovar la estructura del espionaje en Levante. Efectivamente, el Rey Católico heredaba del padre unos servicios de inteligencia que contaban con espías instalados en todos los rincones del Mediterráneo, si bien en la capital del Gran Señor faltaba todavía una red estable de agentes ${ }^{13}$.

El origen del espionaje hispánico hacia el mundo otomano fue una respuesta a la primera gran ofensiva que Solimán el Magnífico protagonizó en los Balcanes y en Levante. Entre la conquista de Rodas y el primer asedio de Viena, el desconocimiento sobre las técnicas militares de los turcos había comprometido el éxito de las batallas, concluídas siempre en favor de los jenízaros ${ }^{14}$. Fue durante la campaña de Solimán contra Viena, cuando la información empezó a jugar un papel esencial. El emperador Carlos V recibía informes constantes, aunque la mayoría de las noticias fueran fruto de circunstancias como acciones de la vanguardia o capturas de prisioneros:

Allende desto fueron preguntados dónde estaua Vuestra Magestad. Respondieron que en la prouincia superior; a esto les dixo el emperador [Solimán] que tenía determinado de seguir a Vuestra Magestad hasta que la alcançasse e prendiesse, consolando a los dichos presos e diziéndoles que estouiessen alegres, pues estauan seguros y fuera de peligro, y oy los despachó e hizo acompañar hasta el hospital ${ }^{15}$.

En la década de los treinta se fundó una organización permanente de espías, cuando en Nápoles fue nombrado el virrey Pedro de Toledo, que junto a Alfonso

11. AlBERI, E.: Relazioni degli ambasciatori veneti al Senato, Florencia, 1840, serie III, volumen I, p. 18.

12. «Nunca dellos se pudo entender la venida de la armada hasta que llegó a los Gelves, aunque muy bien lo sabían». AGS, Estado, Venecia, leg. 1324, d. 87. Garci Hernández a Felipe II, Venecia 18 enero 1561.

13. Ochoa BRun, M. Á.: Historia de la diplomacia española, Madrid, 2003, volumen V.

14. Kumrular, Ö.: Las relaciones entre el Imperio Otomano y la Monarquía Católica entre los años 1520-1535 y el papel de los estados satélites, Estambul, 2003.

15. AGS, Guerra y Marina, leg. 2, d. 174. Los consejeros de Austria Inferior a Carlos V, Viena 27 septiembre 1529. 
Granai Castriota, Marqués de Atripalda, armó una red capaz de obtener un flujo continuo de información en torno al enemigo. Descendiente de exiliados levantinos, el noble fue designado Gobernador de la Terra di Otranto e Bari ya durante el mandato del Cardenal Colonna ${ }^{16}$.

Gracias a sus contactos entre los refugiados griegos, el Marqués de Atripalda constituyó una red de agentes que tenía su principal base en la costa de Pulla. Entonces, desde el tacón de la bota, sus hombres partían con frecuencia hacia Levante para almacenar datos de los turcos, ayudados por familiares y conocidos. En el curso de una década la fórmula más empleada por la inteligencia hispánica fue el viaje del espía, que recorría unos caminos establecidos hasta Constantinopla, donde el enviado intentaba descubrir los proyectos militares del Turco:

Dopuo Apolonio destinato li giorni et mesi passati per lo Illustrissimo Signor Marchese de la Atripalda, da Hotranto in Constantinopoli ad explorar li progressi et andamenti del Gran Turcho cosi per mar com' per terra tanto per Ungaria come per Africa ${ }^{17}$.

El responsable administrativo de Pulla se convirtió así en el responsable del espionaje imperial sobre el Turco ${ }^{18}$. Entre los sucesores de Atripalda destacó Ferrante Loffredo, Marqués de Trevico, que aportó cambios significativos en los servicios secretos de Carlos V. El gobernador desestimó las informaciones proporcionadas por agentes que no estaban asentados en Levante. El Marqués de Trevico favoreció el traslado de espías a islas y puertos, normalmente sujetos a la autoridad de Venecia. El asentamiento en los dominios venecianos permitía también que los confidentes napolitanos entrasen en contacto con la inteligencia de la Serenísima ${ }^{19}$.

En las escalas del Mediterráneo Oriental, los acaudalados de la Corona podían integrarse con naturalidad en la sociedad de acogida, para descubrir con más rapidez y certidumbre las intenciones de la Sublime Puerta. No fue casualidad que la mayoría de los agentes perteneciesen a las comunidades griegas huidas frente al avance otomano. Los exiliados tenían un conocimiento efectivo del mundo levantino, por ejemplo, los miembros de la familia Prohotico, residente durante años en el Archipiélago del Egeo:

16. PetTA, P.: Despoti d'Epiro e principi di Macedonia. Esuli albanesi nell'Italia del Rinascimento, Lecce, 2000 , p. 84.

17. AGS, Estado, Nápoles, leg. 1010, d. 39. Interrogatorio de Dopuo Apolonio, 2 agosto 1531.

18. Aubin, J.: «Une frontière face au péril ottoman: la Terre d'Otrante (1529-1532)», en VeINSTEIN G.: Soliman le Magnifique, et son temps, París, 1992, pp. 465-484.

19. Preto, P.: I servizi segreti di Venezia, Milán, 1994. 
Baldassar Prohotico il quale reside in Levante per servicio de Sua Maestà et de Vostra Eccellenza dice che sono piu anni che se trova servendo per ordine deli ministri de Sua Maestà per dare avisi deli andamenti del Turco et pienamente per ordine del Marchese de Trevico è andato qual Marchese se ritrovava al'hora governatore dele provintie de Terra de Otranto, et Bari ${ }^{20}$.

De todos modos, hasta la debacle de Yerba, la Corona no pudo contar con espías que formasen un grupo permanente en la ciudad de Constantinopla. La fundación fue posible solo gracias a la presencia de cautivos insignes en la capital otomana, que iban a garantizar lealtad y confiabilidad de personajes ya afincados en las orillas del Bósforo. En invierno de 1562, Felipe II explicaba la oportunidad al Duque de Alcalá, en que recaía la gestión económica y política del conjunto:

Por relación y aviso de otros que de Constantinopla han venido, y señaladamente el Capitán Rodrigo Çapata en la relación que nos embiastes deze que un genovés llamado Adán Franquis es persona muy intelligente y sufficiente. Por lo qual se offresciendose al dicho Juan Maria Renzo de bolver a Constantinopla y atender a conservarlas tales personas en nuestra devoción ${ }^{21}$.

Los fundadores eran el genovés de Quíos Adan de Franchi, el veneciano Aurelio Santa Croce y el renegado napolitano Giovanni Agostino Gilli, que ejercía de dragomán en la capital del Turco ${ }^{22}$. Mientras, Giovanni Maria Renzo de San Remo sería el enlace entre la corte virreinal de Nápoles y los agentes de Constantinopla. Frente a las autoridades otomanas los primeros viajes del intermediario estuvieron justificados por la redención de prisioneros, que en aquel momento atraía decenas de mercaderes a Estambul. Un enviado del emperador, Fernando I de Habsburgo, relataba a la corte de Madrid cómo los pagos para la liberación de soldados se habían convertido en un lucroso negocio internacional:

Ho visto tredeci polizze originali de diverse date daltri tanti soldati spagnoli persi alla Giornata de Hieibe e riscatati in Constantinopoli per credito del signor Ambasciador Augenio de Busche che fu della detta Maesta Cesarea appresso al Gran Turco le quali dette cedule o polizze vidi a richiesta de Messere Francesco Licini Mercadante veneziano residente in Pera ${ }^{23}$.

20. Archivio di Stato di Napoli, Regia Camera della Sommaria, Segreteria, Consultationum, busta 2, f. 42v.

21. AGS, Estado, Nápoles, leg. 1052, d. 89. Felipe II a Duque de Alcalá, Madrid 20 enero 1562.

22. Rothman, E. N.: Brokering Empire: Trans-Imperial Subjects between Venice and Istanbul, Ithaca, 2011.

23. AGS, Estado, Costas de África y Levante, leg. 486, s. d. Declaración de Alberto de Vuys, Constantinopla 10 octubre 1562. 
Pronto Giovanni Agostino Gilli se convirtió por sus competencias en el secretario de la red, que él mismo denominó «la Conjura de los Renegados». El agente napolitano llegó a lucir tres nombres distintos en la documentación: el auténtico, el musulmán Hurren Bey y el de conjurado Viban o Urban de Mengrelia. Además de redactar las propuestas de otros espías, el secretario envió una carta suya al Rey Católico tras la primera estancia de Renzo en Constantinopla. El agente ilustraba los planes de los conjurados, que no se limitaban solo a la recogida de información sensible, sino también a acciones de sabotaje contra las instalaciones militares de los otomanos ${ }^{24}$ :

Juan Maria Renzo qual (como a principal autor y tratador de los servicios de Vuestra Majestad que aquí se han tratado y han da exequir), informará del todo particularmente (como conberrá) tanto de la Conjura de estos Renegados en servicio de la Majestad Vuestra, quanto del cremar este tarazenal, si se determinare que es más servicio a cremarlo ${ }^{25}$.

Durante años Giovanni Maria Renzo hizo, al menos, tres viajes a Levante bajo la protección de la Corona. A su primer regreso de Constantinopla el agente gozaba ya de la confianza total por parte del rey. Felipe II no solo le dio cuatro mil ducados y un crédito de otros mil, sino que concedió un salvoconducto al espía, con el cual Renzo pudo moverse sin problema a lo largo de casi todo el espacio italiano. En efecto, la corte de Madrid avisaba de la misión al Virrey de Sicilia, al Duque de Florencia y al embajador en Génova ${ }^{26}$. No obstante su parecer sobre Renzo no era nada benigno, el Duque de Alcalá iba ser el responsable directo del entramado secreto ${ }^{27}$ :

Avisolo a Vuestra Majestad para que se tenga entendido aunque a la verdad el tiempo que aquí le he tractado he comprendido dél [Renzo] (sino me engaño) que no se sacará mucho frutto de los effectos que promete, porque entre otras cosas, me ha paresçido cierto, que los tracta con muy poco secreto ${ }^{28}$.

Desde principio no faltaron críticas en torno a la personalidad de Renzo y sus colaboradores en Constantinopla. Renegados, mercaderes de dudosa moral y familiares de turcos simbolizaban aquel mundo mestizo de la frontera mediterránea, que

24. Sola CaStaño, E.: Los que van y vienen. Información y fronteras en el Mediterráneo clásico del siglo XVI, Alcalá de Henares, 2005, pp. 201-250.

25. AGS, Estado, Costas de África y Levante, leg. 486, s. d. Giovanni Agostino Gilli a Felipe II, Constantinopla 11 noviembre 1562.

26. AGS, Estado, Nápoles, leg. 1052, d. 91. Felipe II a Cosme I De’ Médici, al Virrey de Sicilia y a Gómez Suárez de Figueroa, Madrid 24 enero 1562.

27. «Pareçe hombre de hartas palabras». AGS, Estado, Nápoles, leg. 1056, d. 220. Duque de Alcalá a Felipe II, Nápoles 20 noviembre 1563.

28. AGS, Estado, Nápoles, leg. 1052, d. 40. Duque de Alcalá a Felipe II, Nápoles 3 junio 1562. 
no daba mucha confianza a los responsables políticos de la Monarquía Hispánica. Hasta Nicolò Justiniani, espía y rescatador apreciado por el Virrey de Sicilia, hablaba en estos términos de los conjurados desde la isla de Quíos:

Mi è parso dar noticia a Vostra Eccelentia Illustrissima et mandar la lettera in poter di Mattheo mio figlio al quale di questo negocio le sirvo et ordino a presenti la lettera a Vostra Eccelentia Illustrissima accio quella dia ordine in quello è necessario in servicio et quando per la volontà di Sua Maestà Cattolica fussi di doverlo far' Vostra Illustrissima Eccellentia stia cierta che no mancheria persona di negociare con reputacione cossi in quello come in qualsivoglia altro negocio ${ }^{29}$.

Pero dos acontecimientos afianzaron los proyectos que Renzo y los conjurados habían presentado a la corte de Felipe II. En agosto de 1562 una galera otomana entraba con los pendones bajados en el puerto de Messina. Compuesta por renegados y esclavos cristianos, la tripulación había tomado el control de la embarcación, que pertenecía a Uluj Alí, el Uchali cervantino. Fue en esa ocasión, cuando por primera vez circuló la falsa noticia que el corsario había sido asesinado ${ }^{30}$ :

La galera era de Uluchaly, de quien ya Vuestra Magestad deve tener notiçia que era un Renegado calabrés que ha mucho tiempo que era capitán de las galeras de Dragut y que hazía salidas por estas mares y el que fue quando tocamos en los Gelves la primera vez a Constantinopla y truxo la armada ${ }^{31}$.

Un mes más tarde otra galera turca acababa en manos de marineros renegados y remeros cristianos, esta vez el comandante de la embarcación era Kara Mustafá, Sanjaco de Anatolia, que el sultán había enviado a la isla de Samos para vigilar la construcción de un bastión. Gracias al apoyo de la población autóctona, la tripulación hacía una matanza entre los turcos. El sostén de los griegos resultó fundamental para la huida de la galera a Messina, donde renegados y esclavos llegaron a quince de septiembre ${ }^{32}$.

Sobre todo el levantamiento en la galera de Uluj Alí ponía de manifiesto las oportunidades que la inteligencia hispánica tenía entre los miembros de su casa. Las palabras de Gilli llegaban a ser sintomáticas. Según el secretario de la conjura, si la corte mandaba el virtuoso dinero a Constantinopla, los espías de Felipe II podían alcanzar cualquier logro:

29. AGS, Estado, Sicilia, leg. 1127, d. 93. Nicolò Justiniani al Duque de Medinaceli, Quíos 18 diciembre 1562.

30. Sola Castaño, E.: Uchali, el calabrés tiñoso o el mito del corsario muladí en la frontera, Barcelona, 2010, p. 95.

31. AGS, Estado, Sicilia, leg. 1127, d. 70. Duque de Medinaceli a Felipe II, Monreale 18 agosto 1562.

32. AGS, Estado, Sicilia, leg. 1127, dd. 74-76. Relación, Messina 15 septiembre 1562. 
Qual aconteziendo alguna desdicha de ser descubierto que por birtud de dineros me pueda salvar pues que el dinero tanta birtud tiene y esto lo dexo a arbitrio de los considerados juyzios de Su Católica Magestà y prudente Consejo ${ }^{33}$.

En unos pocos años, junto a toda su familia, Giovanni Maria Renzo se mudó a Nápoles, donde el espía de San Remo podía coordinar con mayor comodidad las relaciones entre los agentes de Constantinopla y la corte virreinal ${ }^{34}$. Así la Conjura de los Renegados operó durante una década, convirtiéndose en el principal canal de información que la Monarquía Hispánica tenía sobre las tramas de los turco-berberiscos, no obstante en 1565 muriesen algunos de los impulsores como el secretario Giovanni Agostino Gilli:

Fa intendere a quella come dopo la morte del Vescovo di Milio, del Corvato et del Gilli, restando sospesi et interrotti l'ordini che s'erano messi in essecutione per servigio di Dio et di Vostra Maestà. Et succedendo nel presente anno la Oportunita et Necessita di tali essecutioni, non è mancato per li buoni amici che sono restati d'essere sollecitato piu et piu volte advertito della oportunita ${ }^{35}$.

Finalmente, Renzo y los conjurados cayeron en desgracia después de los últimos choques militares en aguas mediterráneas. Entre la rebelión morisca de las Alpujarras y la toma otomana de Túnez los juicios de virreyes, funcionarios y militares de Felipe II se volvieron siempre más implacables contra los agentes secretos de Estambul ${ }^{36}$.

El detonante sin duda fue la batalla de Lepanto, en la cual Giovanni Maria Renzo participó en primera persona. Regresado a Nápoles, el agente de San Remo ofreció una lectura bastante original de la memorable jornada, que atrajo las críticas feroces de los altos mandos hispánicos. Según Renzo, la armada de la Liga Santa había ganado en el enfrentamiento naval por la colaboración de sus hombres, que navegaban en las galeras turco-berberiscas, así que los conjurados habían dificultado las maniobras del enemigo ${ }^{37}$. Enfurecido el almirante Luis de Requensens escribió a Felipe II, para desmentir sin giros la reconstrucción del espía:

[Renzo] dize que se halló en la batalla aunque no le vi en ella ni sus renegados hizieron en esta ocasión lo que él en su nombre prometía, antes el Marran Capara quien

33. AGS, Estado, Costas de África y Levante, leg. 486, s. d. Instrucciones de Giovanni Agostino Gilli, Constantinopla 8 noviembre 1562.

34. AGS, Estado, Nápoles, leg. 1054, d. 191. Relación de lo que escribe Juan María Renzo a Su Majestad y al señor Gonzalo Pérez, Nápoles 7 noviembre 1565.

35. AGS, Estado, Nápoles, leg. 1054, d. 189. Giovanni Maria Renzo a Felipe II, Nápoles 7 septiembre 1565.

36. Carnicer García, C. y Rivas Marcos, J.: Espias de Felipe II. Los servicios secretos del Imperio español, Madrid, 2005.

37. AGS, Estado, Sicilia, leg. 1133, d. 124. Relación de Giovanni Maria Renzo, 1571. 
éste llevava carta y grandes promesas de Vuestra Majestad peleó contra nosotros como los demás y le costó la vida ${ }^{38}$.

Las opiniones más negativas en torno a los conjurados venían de Nápoles, que había sido el centro de control sobre la conspiración montada por Renzo. El año anterior a Lepanto había fallecido en la capital partenopea Lope de Mardones, que en la corte hacía de tesorero para asuntos de espionaje. Entonces el virrey nombró en el cargo a Alonso Sánchez, Marqués de Grottola, a quien se ordenó redactar una relación detallada en torno a los gastos de los agentes en Levante ${ }^{39}$.

El marqués daba un veredicto claro sobre la labor de los conjurados. Mientras, el sistema de avisos había tramitado con constancia noticias fidedignas bajo la dirección del difunto Adan de Franchi; sin embargo los proyectos de sabotaje habían resultado siempre inconcluyentes. Por eso Alonso Sánchez sugería la posibilidad que entre los espías de Constantinopla hubiese traidores y estafadores:

Porque la sperientia también lo ha mostrado, haviendo tantos años que dura la plática, y no haviéndose visto effecto ninguno bueno antes conoçiéndose claramente que esta no se movía con otro fin que con pensamientos de sacar cada año dineros de Su Majestad ${ }^{40}$.

El nuevo Virrey de Nápoles, Cardenal Granvela, compartía el análisis del marqués. En efecto, a unos meses de distancia, una carta tajante del eclesiástico llegaba al escritorio de Felipe II. Si bien estaba ocupado con la salida inminente de la armada, que en octubre iba a vencer a la flota del sultán, el virrey no olvidaba el informe de Alonso Sánchez. Granvela no ocultaba la sospecha que los conjurados fueran agentes dobles:

Por la relación que ha hecho el Thesorero que ha tenido cargo de las spías, que lo que hasta agora ha havido es cosa de mucha costa y de poco fundamento, y por mi tengo que esta gente nos engaña, y ymporta infinito para el año que viene saber más de rayz lo que passa ${ }^{41}$.

La victoria de la Liga Santa complicó aún más las tareas de los espías hispánicos. Las autoridades otomanas acrecentaron los controles sobre extranjeros y renegados, asentados en Estambul. Entre varios fue descubierto un agente con una larga trayectoria en la inteligencia del Rey Católico: el genovés Gregorio Bragante,

38. AGS, Estado, Sicilia, leg. 1140, d. 98. Luis de Requensens a Felipe II, Messina 9 noviembre 1571.

39. InTORCIA, G.: Magistrature nel Regno di Napoli. Analisi prosopografica secoli XVI-XVII, Nápoles, 1987, p. 375.

40. AGS, Estado, Nápoles, leg. 1060, d. 129. Relación de Alonso Sánchez, 9 mayo 1571.

41. AGS, Estado, Nápoles, leg. 1060, d. 51. Cardinal Granvela a Felipe II, Nápoles 18 agosto 1571. 
alias Morat Agá, justiciado por lesa majestad. Los conjurados se enfrentaban a enormes dificultades si enviaban despachos más allá de la frontera:

Non obstante che abiamo avuto et abiamo molte difichulta contrarie stante questa guerra, che non posiamo drezar con prestezza li avisi como se facea li anni passati perche non po andar nisun fante de qui a Ragusi senza comandamento del Gran Signor pena de morte; non solamente de qui a Ragusi ma in ogni altro locho. Con ogni minima letera sariem impalati ${ }^{42}$.

Además de las críticas internas y de la represión turca, la red de Giovanni Maria Renzo se vio perjudicada por el nuevo marco, que iba a encuadrar las relaciones entre la Monarquía Hispánica y la Sublime Puerta. Los dos gigantes del Mediterráneo estaban agotados por un estado de guerra permanente, que menoscababa recursos naturales y financieros ${ }^{43}$.

Entretanto nuevos y viejos enemigos presionaban los confines de ambos imperios. El sultán tenía la necesidad de detener las incursiones portuguesas en el Océano Índico, mientras el Sah de Persia nunca había suspendido sus correrías en las provincias orientales del Gran Señor ${ }^{44}$. Las dos circunstancias fueron repetidas hasta el infinito por espías, vinculados a diplomáticos adversos a la tregua con el Turco, así los contrarios a cualquier pacto con los otomanos respaldaban la prosecución de la guerra en el espacio mediterráneo ${ }^{45}$.

Felipe II por su parte arrastraba el lastre de la insubordinación flamenca, que tanto había pesado en las decisiones del soberano sobre el ajedrez del Mediterráneo. A parte, la nefasta empresa de Sebastián I de Portugal contra Fez abrío un escenario inesperado al Rey Católico, que con la muerte del sobrino tenía la justificación ideal para tomar el inmenso imperio colonial de Lisboa ${ }^{46}$.

Aunque fuera desmentida en cualquier ocasión pública, tanto Madrid como Estambul sentían la necesidad urgente de llegar a un compromiso diplomático, que diera estabilidad al área mediterránea. De hecho, el bienio 1573-74 ratificó con las campañas bélicas contra Túnez que ninguno de los contrincantes tenía la fuerza suficiente para amplificar la propia influencia en perjuicio del otro $^{47}$.

42. AGS, Estado, Costas de África y Levante, leg. 487, s. d. Avisos para Felipe II, Constantinopla 1572.

43. Skilliter, S. A.: «The Hispano-Ottoman Armistice of 1581», en Bosworth, C. E.: Iran and Islam, Edimburgo, 1971, pp. 491-515.

44. IMBER, C.: The Ottoman Empire, 1300-1650: the structure of power, Basingstoke, 2002, pp. 63-68.

45. AGS, Estado, Nápoles, leg. 1074, d. 10. Relación de un espía, Venecia 13 abril 1577.

46. Bunes Ibarra, M. Á. y García Hernán, E.: «La muerte de Don Sebastián de Portugal y el mundo mediterráneo de finales del siglo XVI», Hispania. Revista española de historia, 54/187, 1994, pp. 447-465.

47. García Hernán, E.: «La conquista y pérdida de Túnez por don Juan de Austria (1573-1574)», en CANDIANI, G. y Lo BASSO, L.: Mutazioni e permanenze nella storia navale del Mediterraneo (sec. XVI-XIX), Milán, 2010, pp. 39-95. 
En unos pocos años iban a comenzar unos coloquios que concluyeron con la histórica tregua entre el paladín de la Cristiandad y el defensor del Islam. También en estas negociaciones fueron fundamentales, al menos en principio, los agentes de Renzo, particularmente el veneciano Aurelio Santa Croce; si bien los conjurados fueron apartados totalmente de las conversaciones, cuando los colaboradores de Felipe II estimaron en el Consejo de Estado que el pacto era viable y ventajoso ${ }^{48}$.

Casi todos los miembros de la red tuvieron un destino infeliz, varios murieron en campañas militares, otros fueron descubiertos y justiciados por los otomanos. El inventor Giovanni Maria Renzo fue alejado de las actividades secretas en Levante, finalmente el espía de San Remo se quedó en Nápoles donde falleció en $1577^{49}$.

Desembarcados en tierras del Rey Católico, algunos agentes como Santa Croce fueron incluso encarcelados después de años al servicio de la Corona. En 1579 el conjurado veneciano acabó preso en la cárcel de Madrid. Las acusaciones hacían referencia a la liberación de unos esclavos, un negocio acontecido en Nápoles y que había dañado al Marqués de Santa Cruz, Álvaro de Bazán. Pero el motivo verdadero de la reclusión estaba relacionado sin duda con las últimas intrigas de Aurelio, que era tachado de espía doble:

Mi resta achora a suplichar a Vostra Maestà che si digni considerare che io sono uscito de caxa mia sono hormai 3 anni. Et lassata tuti li mei negocii con gran rovina detta caxa mia. Et misso la mia vita in tanti rissigi et piricollo ${ }^{50}$.

En 1581 Felipe II puso la palabra fin a la red fundada por Renzo, cuando el soberano apoyó una orden de Marcantonio Colonna, Virrey de Sicilia. En Estambul, de hecho, la negociaciones entre el enviado de Su Majestad, Giovanni Marigliani, y el Gran Visir habían alcanzado un compromiso que garantizaba una cierta tranquilidad en el Mediterráneo y no excusaba los gastos excesivos en los sueldos de espías ${ }^{51}$.

Realmente, hacía años que la corte virreinal de Nápoles debatía en torno a nuevas fórmulas que hiciesen más económico y seguro el espionaje de Levante. En 1577 Bartolomeo Bruti tuvo varios encuentros con el Marqués de Mondéjar,

48. Marcos Rivas, J. y Carnicer García, C.: Espionaje y traición en el reinado de Felipe II: la bistoria del vallisoletano Martín de Acuña, Valladolid, 2001.

49. «En lugar de Juan Maria Renzo, que murió». AGS, Estado, Nápoles, leg. 1073, d. 171. Diego d'Esquivo a Felipe II, Nápoles 1577.

50. AGS, Estado, Nápoles, leg. 1080, d. 62. Aurelio Santa Croce a Felipe II, cárcel de Madrid 18 noviembre 1579 .

51. Tejada Carrasco, C.: «Memoriales de excautivos: una mirada española de Constantinopla tras Lepanto», Numhauser, P. y Forniés CaSAls, J. F.: Escrituras Silenciadas. El paesaje como historiografía, Alcalá de Henares, 2013, pp. 381-393. 
en los que el agente albanés propuso la sustitución de los griegos ortodoxos por agentes eslavos de religión católica. El proyecto era defendido por el mismo Aurelio Santa Croce:

Aurelio de Santa Cruz le dió [a Bruti] una carta para el Virrey de Nápoles para que se tratasse con el algún nuevo camino para tener avisos, por estar cerrado el passo por las guardias que el primer Baxa avía puesto en ellos a causa de los esclavos que se huyan fue a darle carta al dicho Virrey y memoria de los caminos que podía aver ${ }^{52}$.

Pero Felipe II y sus colaboradores tenían pensada una renovación completa de la inteligencia que no se limitaba al cambio de agentes y caminos. Asimismo, la decisión del soberano sobre la red secreta del Mediterráneo Oriental fue tomada en un momento y en un lugar claves, que representaban con una circunstancia brillante la mudanza definitiva de los intereses hispánicos hacia el Atlántico ${ }^{53}$.

En efecto, Su Majestad escribía a Marcantonio Colonna desde Tomar, donde estaba a la espera de que la nobleza lusa confíara en sus manos la Corona de Portugal. Felipe II compartía las sugerencias del virrey cuando ordenaba que se suspendiesen los sueldos de los espías en Levante, porque las informaciones sobre los otomanos pasaban ahora con más facilidad a través otros canales, bien Giovanni Marigliani, bien vía Venecia:

Hase recebido vuestras tres cartas de 22 de octubre y otra de primero de noviembre, en la una de las quales dezís las causas porque havéys hecho quitar los salarios a las personas que los tenían en Xio y otras yslas del Archipiélago con cargo de embiar avisos que ha parescido bien, pues quame los suyos llegarán y mucho antes dezís que se sabrá ay por la vía de Venecia ${ }^{54}$.

\section{LA METAMORFOSIS DE UN FRANCISCANO: DE INQUISIDOR EN TÚNEZ A ESPÍA EN} MADRID

Cuando la Sublime Puerta conquistó definitivamente Túnez, las armadas turco-berberiscas estaban guiadas por dos renegados de origen italiano, el genovés Sinan Bajá y el calabrés Uluj Alí. La victoria de los otomanos fue llamativa, las defensas tanto de La Goleta como de la capital tunecina resultaron ineficaces, así,

52. AGS, Estado, Costas de África y Levante, leg. 488, s./f. Memoriale di Bruti, 1577.

53. BouZA, F.: Portugal en la monarquía hispánica (1580-1640). Felipe II, las Cortes de Tomar y la génesis del Portugal católico, Madrid, 1987. 1581.

54. AGS, Estado, Sicilia, leg. 1151, d. 245. Felipe II a Marc'Antonio Colonna, Tomar 10 abril 
una vez más, sobre las galeras del sultán viajaron miles de cautivos cristianos, que fueron transportados a Estambul como esclavos ${ }^{55}$.

Entre muchos otros estaba el fraile mallorquín Diego. El eclesiástico balear había desembarcado el año anterior en Túnez, porque don Juan de Austria le había encomendado un papel de envergadura en la posesión africana: Diego iba a ser el Vicario General y Comisario del Santo Oficio en un área donde la casi totalidad de los súbditos eran musulmanes ${ }^{56}$.

El cometido tan significativo fue asignado al monje, con toda probabilidad, gracias a Miguel de Serviá, confesor del almirante, que también era mallorquín y franciscano. Durante aquellos años Serviá tuvo una ascendiente y notable influencia sobre don Juan, por lo que sus sugerencias contaron mucho para el artífice del destino ${ }^{57}$ :

Hallándome yo en la dicha fuerza [La Goleta], cuando el serenísimo señor don Juan de Austria vino con su armada y tomó a la ciudad de Túnez, que estaba ocupada de turcos, quedó por Vicario General de la fuerza y Comisario del Santo Oficio de la Inquisición el muy reverendo padre fray Diego de Mallorca, de la orden de San Francisco ${ }^{58}$.

Mientras Diego estuvo en Túnez, el franciscano desarrolló su actividad evangelizadora con perseverancia, los testimonios coincidían en alabar la labor del mallorquín, subrayando con fuerza sus tareas pastorales entre infieles. Alojado en La Goleta ya desde hacía unos años, el carmelita Nicolo de Sotera recordaba como Diego había convertido a cinco judíos y varios moros durante su estancia en tierra de África:

Patre fra Diego de Mayorca, Vicario Inquisitore de detta forteza, lasciato del Serenissimo Signor don Juan de Austria en el suo regimiento, si a portato da vero pastore e a governato la deta iglesia, con fari sermoni, predicationi et tuti altri cose nessesari a la utilità di quelle animi, del che per soy predicationi et sermoni convertiò 5 judei et altri mori ${ }^{59}$.

55. GonzÁlez Castrillo, R.: «La pérdida de La Goleta y Túnez en 1574, y otros sucesos de historia otomana, narrados por un testigo presencial Alonso de Salamanca», Anaquel de estudios árabes, 3, 1992, pp. 247-286.

56. AlONSO ACERO, B.: «Heterodoxia e Inquisición en las sociedades hispanas de Berbería, siglos XVI-XVII», Hispania sacra, 55/112, 2003, pp. 481-500.

57. Serviá, M.: «Relación de los sucesos de la Armada de la Santa Liga, y entre ellos el de la batalla de Lepanto, desde 1571 hasta el 1574 inclusive», en SALVÁ, M. y SaINZ DE Baranda, P.: Collección de Documentos Inéditos para la Historia de España, Madrid, 1847, tomo XI, pp. 359-454. British Library, 9195 ccc.

58. AGS, Estado, Sicilia, leg. 1144, d. 206. Testimonio de Bartolomé de Salamanca, Nápoles 6 julio 1575 .

59. AGS, Estado, Sicilia, leg. 1144, d. 206. Testimonio de Nicolo de Sotera, Constantinopla 30 diciembre 1574. 
Pero las palabras más lisonjeadas sobre el franciscano hacían referencia a su participación en la batalla para la defensa del bastión, cuando el ejército turcoberberisco asaltó las posiciones de las tropas hispanas. Diego no solo animaba a los soldados y ayudaba a los heridos, sino que combatía al lado de los sitiados. En su testificación a favor del monje, Paulo Moya mencionaba una escena de enorme carga emotiva. El médico de Palermo señalaba cómo Diego iba entre los militares de la fortaleza con una cruz en la mano izquierda, mientras que en la derecha llevaba una espada:

Aversi pasato si bene in tuti suoi actione nesesarie a deto officio sensa encandalo alcuno et averse pasato come et quanto li sopra deti testimonii testificano et più maximamente nel tempo que se conbatia con sua croce in mano siniestra et in la dextra sua espata et sempre nel bastione, di note et di giorno, se trovaba prontissimo ${ }^{60}$.

Durante el cerco de La Goleta, Diego de Mallorca fue alcanzado por una flecha de los arqueros otomanos. El impacto le provocó una herida en el muslo izquierdo que le dejaría secuelas. La imagen era recordada con admiración por otro carmelita, Juan de Plasencia, quien también había sido capellán en el fuerte de Su Majestad:

Y estando sitiada la dicha fuerza, al dicho padre Vicario le vi ir por los bestiones y lugares peligrosos predicando y animando los soldados y recogiendo los muertos $\mathrm{y}$ heridos. Y le hirieron de un flechazo en el muslo izquierdo ${ }^{61}$.

Cuando llegó a Constantinopla, fray Diego encontró varios personajes de la élite turca. Los coloquios fueron favorecidos por unos parientes del mallorquín. Una tía del religioso estaba casada con un bajá de la corte otomana, mientras su primo Marc' Antonio, alias Hasan Agá, ejercía de tesorero en la grande casa de Sokollu Mehmet Bajá, que desde hacía años era el Gran Visir del imperio.

Así el fraile conoció a Leonora Spalletta, una italiana casada con Piali Bajá, que más tarde iba a escribir una carta a Ana de Austria, esposa de Felipe II, donde aseguraba devoción y lealtad de Diego. En un primer momento la consorte del almirante otomano quiso patrocinar al franciscano para que llegase al mando del Patriarcado de Constantinopla, pero el mallorquín se negó a las proposiciones:

Aunque yo sea de las mínimas criadas del Gran Señor Sultán Morat, estoy siempre aparejada en servir a vuestra serenísima alteza, rogando a Dios le dé la Monarquía general aumento siempre su estado. Per quanto, serenísima Señora, acá habemos procurado que se quedase el dicho padre Vicario [Diego de Mallorca], portador de

60. AGS, Estado, Sicilia, leg. 1144, d. 206. Testimonio de Paulo Moya, Constantinopla 2 enero 1575.

61. AGS, Estado, Sicilia, leg. 1144, d. 206. Testimonio de Juan de Plasencia, Constantinopla 27 diciembre 1574 . 
la presente, por ser tal persona, obligándonos que quedándose acabaríamos con el Gran Señor de hacerle Patriarca de Constantinopla ${ }^{62}$.

En el siglo xvi la presencia de mujeres cripto-cristianas en los círculos más prestigiosos de Constantinopla fue bastante característica, en más de una ocasión su autoridad protegió a los agentes europeos en apuros. Por ejemplo un caso muy sugestivo fue la madre de Ibrahim Bajá, quien entre 1523 y 1536 estuvo al mando del Imperio Otomano en calidad de Gran Visir ${ }^{63}$. Cuando los soldados turcos encarcelaron a Gregorio de Cecchi, un espía enviado por el Marqués de Atripalda, la anciana ordenó su liberación y luego le amparó en su casa:

Y fue libertado a intercesión de la Madre de Abrayn Bassá que es cristiana y biue como cristiana y tiene si yglesia y muchas vezes el patriarcha va a dezir missa allá. Y que después de libre estuvo siempre en casa dela detta Madre por poder mejor entender y con seguridad ver ${ }^{64}$.

Diego de Mallorca contaba entonces con el favor de sus familiares, sobre todo Hasan Agá le proporcionó una ayuda esencial en aquel contexto hostil. El secretario del Gran Visir querría volver a la Cristiandad, así que prometía su contribución al espionaje hispánico. De todos modos, el renegado no quería que en la nueva red participasen los antiguos conjurados, de los cuales no tenía ninguna confianza.

La Corona tenía delante una gran oportunidad, porque desde su posición Hasan Agá habría tenido la ocasión de observar sin trabas el corazón del poder otomano. El primo del fraile solamente pedía al Rey Católico que justificase su causa y la de su madre frente al Sumo Pontífice:

A la quale [Felipe II] bramo servire per insino a la morte in tutto quel sarà necessario. Et per questo la supplico mi favoresca con una lettera avisar' Sua Sanctita, accio mi mandi la sua Sua benedittione et larga absolutione. La quale me la portarà il predetto Padre Vicario per ch'a Sua Reverentia. Et non ad altro ho fede, il che Sua Maestà facendo mi farà singular favore non tanto a me, ma ancho a mia madre et ad altre Signore et moglie di questi Bassa ${ }^{65}$.

El cautiverio de Diego de Mallorca duró muy poco. Si bien permaneció muchos meses en Constantinopla, el franciscano fue rescatado en diciembre de

62. AGS, Estado, Sicilia, leg. 1144, d. 207. La mujer de Piali Bajá a Ana de Austria, Constantinopla 24 febrero1575.

63. Turan, E.: «The Marriage of Ibrahim Pasha (ca. 1495-1536). The Rise of Sultan Süleyman's Favorite to the Grand Vizierate and the Politics of the Elites in the Early Sixteenth-Century Ottoman Empire», Turcica, 41, 2009, pp. 3-36.

64. AGS, Estado, Costas de África y Levante, leg. 462, s. d. Relación de Gregorio Cecchi, 17 julio 1535 .

65. AGS, Estado, Sicilia, leg. 1144, d. 209. Hasan Agá a Felipe II, Constantinopla 23 marzo 1575. 
1574. El fraile estuvo en los baños turcos como esclavo poco más de un mes, ya que la flota del sultán había vuelto de Túnez a mediados de noviembre ${ }^{66}$. Pero el religioso siguió frecuentando los lugares de los prisioneros cristianos, donde Diego predicaba el evangelio como apuntaban varios testigos:

Juan de Murcia, Escribano de los cristianos de Mahamete Bajá, hago fee cómo el padre Vicario de la Goleta ha andado predicando por los baños y cautiverios de Estambul y haciendo su oficio como muy buen cristiano, y porque es verdad lo firmo yo por todos de mi nombre Juan de Murcia ${ }^{67}$.

Los deponentes en favor del franciscano no eran solo soldados o gente de a pie que vivían como esclavos en la capital turca, sino que el mismo Gabrio Serbelloni, Capitán General de Túnez, y el embajador veneciano en la Puerta del Gran Turco, Antonio Tiépolo, reiteraban las palabras benévolas en favor de fray Diego:

Facemo fede a cada uno che vederà la presente nostre come per relacione dell'Illustre signori Gabrio de Serbeloni, già governatore et del Signore Andrea Salazar, maestro di campo in Túnez, et anco per una scritura che appare firmata de diverse mani de honorati signori, siamo certificati il Reverendo patre fra Diego de Mallorca, dell'ordine de San Francesco ${ }^{68}$.

Finalmente la liberación de Diego se debía a la intercesión de otro franciscano. Originario de la isla griega de Quíos, fray Antonio estaba asentado en el convento de Pera, donde había oído la labor que su cofrade hacía entre los cautivos más desfavorecidos. El monje se ponía entonces en contacto con Diego de Mallorca para que su redención fuera más rápida ${ }^{69}$.

Ahí envío un traslado de un testimonio que se hizo en Constantinopla por el escribano de su majestad, nuestro señor, de cómo serví en la Goleta el tiempo que en ella estuve. Y también de cómo me rescaté por medio del padre comisario de San Francisco de Gálata ${ }^{70}$.

El franciscano mallorquín abandonaba Constantinopla rumbo Nápoles en junio de 1575, consigo llevaba unas cartas que le iban a cambiar la vida. Durante

66. «A los 15 llegó aquí Ulachiali y Sinan Baxa con la armada». AGS, Estado, Costas de África y Levante, leg. 488, s. d. Espía a Felipe II, Constantinopla 17 noviembre 1574.

67. AGS, Estado, Sicilia, leg. 1144, d. 209. Declaración de Juan de Murcia, Constantinopla 20 enero 1575 .

68. AGS, Estado, Sicilia, leg. 1144, d. 209. Certificación de Antonio Tiépolo, baylo veneciano, Pera 22 enero 1575. 1575.

69. AGS, Estado, Sicilia, leg. 1144, d. 209. Declaración de Fray Antonio de Quíos, Pera 26 enero

70. AGS, Estado, Sicilia, leg. 1144, d. 211. Diego de Mallorca a Antonio de Toledo, Gran prior de Malta, Madrid 8 diciembre 1575. 
meses el franciscano detalló las angustias de los cautivos cristianos en los baños turcos a otros monjes y a funcionarios de la corte virreinal.

Pero el encuentro más importante fue con don Juan de Austria. El hijo natural de Carlos V estaba todavía en Nápoles, donde con el cargo de Comandante General gestionaba la flota mediterránea ${ }^{71}$. Los coloquios debieron de ser muy amigables, probablemente los dos recordaron a Miguel de Serviá, que el año anterior había fallecido en Palermo. Tras la lectura de las cartas escritas en Constantinopla, don Juan no dudó que Diego podía convertirse en una pieza clave para remplazar los descreditados conjurados de Renzo.

Así el almirante escribió a Felipe II una misiva, donde el fraile era llamado Domingo. En la epístola, don Juan repetía el valor de los contactos que el franciscano tenía en los círculos más cercanos al sultán. Al fin, Su Alteza suplicaba a su hermano que intercediese por el monje con el papa, Gregorio XIII, de manera que fray Diego no tuviese que responder a ninguno de sus superiores respecto a futuros desplazamientos:

Pero, de cualquier manera, será bien que Vuestra Majestad mande agradecer al dicho fray Domingo [Diego] el buen celo con que toma trabajo de hacer esta jornada, dando orden a sus prelados y superiores que no le molesten el tiempo que anduviere ocupado en estos negocios, pues son de tal cualidad e importancia que no merece menos andando en ellos que si se estuviese disciplinando ${ }^{72}$.

En diciembre Diego de Mallorca estaba en Madrid. Desde un convento franciscano el fraile enviaba una carta a don Antonio de Toledo, Gran Prior de Malta. El principal objetivo del despacho era una intervención del prelado para que Felipe II recibiese lo más rápidamente posible al monje:

Vuestra Ilustrísima señoría tomará ese trabajo de leer ese traslado por amor de Cristo nuestro redentor, y por hacerme a mí, su servidor, la merced. Y leído informará a Su Majestad suplicándole me despida lo más presto que sea posible porque el tiempo es breve y el camino es largo ${ }^{73}$.

En conclusión, el encuentro entre el franciscano y el rey se hizo en el monasterio del Escorial, donde Diego de Mallorca consignó a Felipe II los avisos que traía de Constantinopla. La noticias eran ya bastante viejas y conocidas en la corte del Rey Católico, las informaciones trataban asuntos de diversa índole: los apoyos franceses al Turco después de Lepanto, las maniobras galas en Polonia,

71. Bennassar, B.: Don Juan de Austria. Un héroe para un imperio, Madrid, 2000.

72. AGS, Estado, Sicilia, leg. 1144, d. 210. Don Juan de Austria a Felipe II, Nápoles 7 septiembre 1575.

73. AGS, Estado, Sicilia, leg. 1144, d. 211. Diego de Mallorca a Antonio de Toledo, Gran prior de Malta, Madrid 8 diciembre 1575. 
las tramas de los rebeldes genoveses y las propuestas elaboradas en el Diván para reorganizar la armada naval ${ }^{74}$.

Pero la introducción del mensaje despertó inevitablemente el interés de Su Majestad, que en aquella época empujaba a sus agentes a un negociado con los turcos con el propósito de una tregua disimulada. Un confidente tan cercano al Gran Visir podía ser un enlace vital para descubrir las verdaderas intenciones de Sokollu Mehmet Bajá en la negociación con Giovanni Marigliani: «Trata cómo fue a Constantinopla. Y que tiene allí un primo suyo renegado que tiene mucha mano en los negocios y que dice los avisos que este su primo le dio» ${ }^{75}$.

Al final de año Felipe II trasmitía un nuevo despacho a don Juan de Austria, que el mismo franciscano llevaba a Nápoles. El soberano aceptaba las propuestas del fraile, aunque Su Majestad dejaba la operación en manos del hermano, que desde Nápoles tenía más posibilidades de controlar los movimientos de Diego. Además el rey ordenaba a don Juan que contactase a Juan de Zúñiga, Comendador Mayor de Castilla, entonces embajador en la corte pontificia de Roma. El diplomático debía pedir al papa que concediese un permiso al franciscano mientras empeñaba tareas de espionaje:

Será bien que vos enviéis a suplicar a Su Santidad por medio de don Juan de Zúñiga sea servido de conceder un breve para que el tiempo que el dicho fray Domingo [Diego] de Mallorca anduviere encargado por orden mía en las cosas que vos le encomendáredes, ningún superior suyo se lo estorbe ni impida, ni incurra por ello en pena ninguna, el tiempo que como está dicho se ocupará en esto ${ }^{76}$.

Junto a la carta para don Juan de Austria, Felipe II enviaba también dos epístolas para los capitanes Juan de Vergara y Domingo Larrauri. Los oficiales tenían que favorecer el tránsito de Diego de Mallorca hacia la península italiana. Particularmente, el rey ordenaba a Larrauri que transportase en sus galeras al fraile hasta el lugar donde estaba el almirante:

A fray Domingo [Diego] de Mallorca he ordenado que vuelva a Italia a servirme en lo que el ilustrísimo don Juan de Austria, mi hermano, le ordena él, y que vaya en las galeras de vuestro cargo si las pudieren alcanzar. Yo os encargo y mando que le recojáis en ellas y llevéis hasta donde estuviere el dicho don Juan mi hermano,

74. TÜRKÇELIK, E.: «Estambul y las provincias berberiscas en el tránsito de los siglos XVI al XVII», en Bunes Ibarra, M. Á. y Alonso Acero, B.: Orán. Historia de la corte chica, Madrid, 2011, pp. 173-194.

75. AGS, Estado, Sicilia, leg. 1144, d. 212. Avisos de Diego de Mallorca, 1575.

76. AGS, Estado, Sicilia, leg. 1144, d. 332. Felipe II a don Juan de Austria, San Lorenzo 30 diciembre 1575 . 
haciéndole todo buen acogimiento y recogimiento, como se debe a persona de su hábito ${ }^{77}$.

Cuando encontró a Su Majestad, Diego de Mallorca dio una información al rey, que mereció una mención aparte en otra carta de Felipe II para su hermano. Según el franciscano el último general de Chikly, fortaleza en el lago de Túnez, estaba colaborando con los otomanos. El rey exigía a don Juan de Austria que se encargase del delicado y enojoso asunto:

Don Juan Çanoguera ha tenido inteligencia con turcos y moros. Y esto se entendió bien cuando el suceso de la Goleta, como más particularmente lo veréis por la dicha relación del dicho fraile. Y porque también esto se ha confirmado por otra vía, me ha parecido avisaros de ello para que procuréis de saber la verdad; porque tal cosa, si lo fuese, no quede sin castigo, como lo merece ${ }^{78}$.

\section{Montar una NUEVA RED PARA LA INFORMACIÓN SECRETA}

Después de dos años, pero Diego de Mallorca estaba todavía en Nápoles, el fraile había elegido como residencia el monasterio de su orden, denominado Santa María la Nova, que era uno de los institutos religiosos más célebres e importantes de la ciudad ${ }^{79}$.

Las promesas de Su Majestad seguían incumplidas, así que el franciscano decidió escribir una nueva carta al soberano donde recordaba la trascendencia de sus proyectos, que necesitaban mayor prontitud de ejecución por parte de la corte. La misiva estaba llena de referencias bíblicas que gustaron a un rey tan piadoso como Felipe II $^{80}$. El monje se comparaba a los humildes del Antiguo Testamento, con los cuales dios había derrocado los enemigos de la fe:

[Dios] quiso por medio de unos exploradores, gente común, humilde, no nada conocida, traer a las manos del famosísimo príncipe Josué a la superba ciudad de Jericó. No con soldados y grande ejército, sino con ranas y mosquitos abatió las

77. AGS, Estado, Sicilia, leg. 1144, d. 334. Felipe II a Domingo de Larrauri, San Lorenzo 30 diciembre 1575.

78. AGS, Estado, Sicilia, leg. 1144, d. 335. Felipe II a don Juan de Austria, San Lorenzo 30 diciembre 1575 .

79. Testa, T.: Serafici Fragmenti della provincia monastica francescana di Napoli, siglo XVII. El manuscrito está en el Archivio dei Frati Minori di Napoli,ubicado en el precioso monasterio de Santa Clara en Nápoles.

80. SÁnchez-Molero, J. L. G. y Alonso Acero, B.: «Alá en la corte de un príncipe cristiano: el horizonte musulmán en la formación de Felipe II (1532-1557)», Torre de los Lujanes: Boletín de la Real Sociedad Económica Matritense de Amigos del País, 35, 1998, pp. 109-140. 
fuerzas del Rey Pharaon. Con una piedra pequeñuela y una honda trujo a los pies de David un fortísimo gigante ${ }^{81}$.

En aquel invierno de 1577 fray Diego trasmitió el primer aviso a Su Majestad, las noticias habían sido recogidas por su primo Hasan Agá, que en julio le había enviado un despacho cifrado a Nápoles a través de Jerónimo Combi.

El contenido del aviso abarcaba muchos temas. En primer lugar se destacaba la paz entre los sectores de la élite genovesa, que había sido acogida con disgusto y decepción entre los dignatarios de Constantinopla. Además el renegado apuntaba las novedades procedentes de Marruecos, donde Muley Maluc se había hecho con el trono de Fez gracias al apoyo del sultán. La preocupación estaba respaldada por el Duque de Sessa, almirante de la flota napolitana, que se había convertido en el referente de la inteligencia a perjuicio del virrey Mondéjar:

Si la armada pasase a Poniente, es de tener por cierto que sería continuando las inteligencias que se ha dicho que tenía con el Rey de Fez. Y aunque tengo por sin duda que Vuestra Majestad habrá mandado prevenir lo que conviene para la defensa de Orán y Masalquivir, y para estorbar que el enemigo no tome pie en la laguna de Melilla ${ }^{82}$.

En el aviso de Hasan Agá no faltaban tampoco referencias a los Balcanes, Hungría y Venecia. Pero en los grupos dirigentes de la Sublime Puerta continuaban las diferencias de opinión respecto a la prioridad de intervención entre el Mediterráneo y Persia, donde habían proclamado al Shah Ismail II, así que Hasan Agá no podía garantizar la salida de la flota otomana hacia Poniente. Las noticias de maniobras en Oriente Medio estaban confirmadas por vías ya consolidadas. En efecto, la red del secretario en Venecia, Cristóbal Salazar, enviaba a Felipe II un despacho con la misma duda en torno a los movimientos de la armada turcoberberisca:

Que el Baylo de venecianos escribe que la guerra es cierta en Persia a lo que parescia. Porque habiendo deseado Mehemet Bassá disuadir la guerra, porque por ella ganarian reputación los Bassás sus émulos, por tenellos bajos, agora procurará que Mustafa, que es su competidor, se enviase a los confines para acelerar las provisiones de la guerra. A la cual se via mala voluntad por las cabezas principales, porque decian que ninguno volveria a su casa ${ }^{83}$.

El mayor temor de Hasan Agá, sin embargo, estaba representado por la presencia de moriscos en el palacio del sultán Murad III, los súbditos cripto-musulmanes

81. AGS, Estado, Nápoles, leg. 1073, d. 10. Diego de Mallorca a Felipe II, Nápoles 7 enero 1577.

82. AGS, Estado, Nápoles, leg. 1075, d. 21. Duque de Sessa a Felipe II, Nápoles 18 enero 1577.

83. AGS, Estado, Nápoles, leg. 1077, d. 13. Avisos de Costantinopla via Venecia, 7 enero 1578. 
de Felipe II querían el sostén del Gran Turco para rebelarse contra su propio rey. Los impulsores del tratado eran los miembros de la familia valenciana Izquierdo, ya bajo control de los inquisidores en el Reino de Aragón ${ }^{84}$. De hecho, los espías de Berbería llevaban años repitiendo el peligro que representaban los contactos entre moriscos y otomanos a través la plaza de Argel:

Quitábase la correspondencia que los moriscos destos Reinos y de Aragón y Valencia, siendo en tanto número, y estando, como diz que están, armados y ejercitados, tienen con los de Argel. Y los avisos que por aquella vía se dan al Turco de las cosas de acá. Y las galeras que se entretienen en estos Reinos sólo por causa de las fustas de Argel, podrán servir en Nápoles y Sicilia, donde conviene que esté la fuerza del Armada ${ }^{85}$.

Finalmente, en la carta de Diego para Su Majestad el aspecto más subrayado era la disposición de Hasan Agá a favorecer el espionaje hispánico, que se habría beneficiado de la confianza gozada por un hombre tan cercano al Gran Visir. La única petición del renegado por el momento era un veloz traslado del fraile a Constantinopla:

Encarga el dicho Zanaga al fraile su primo que avise de todo esto a su majestad y que con la respuesta y resolución vaya luego allá porque por su mano quiere dar avisos y servir al rey. Aunque no se cumpla con él lo que se le prometió ${ }^{86}$.

En la nueva red constituida por Diego de Mallorca y Hasan Agá, un papel fundamental era asignado al capitán Jerónimo Combi, que había de ser el heraldo entre Constantinopla y Nápoles. En la corte se tomó información en torno al espía que iba a desempeñar un rol delicado, así que era necesario confiar totalmente en el agente:

Lo que en sustancia contienen los memoriales del Combi, es presentar los trabajos y tormentos que pasó en la prisión por no ser descubierto, que era de los que servían a Su Magestad en Constantinopla. El deseo que tiene Zanaga, renegado, secretario del Primer Bajá, de escribir a Su Magd. El cual ofrece de dar avisos de mucha importancia por medio de fray Diego de Mallorca, su primo, a quien pide se envie allá ${ }^{87}$.

84. Hess, A. C: «The Moriscos: An Ottoman Fifth Column in Sixteenth-Century Spain», American Historical Review, 74:1, 1968, pp. 1-25.

85. AGS, Estado, Costas de África y Levante, leg. 488, s. d. Discurso sobre lo mucho que conviene hacer la empresa de Argel. Argel, 1575.

86. AGS, Estado, Nápoles, leg. 1074, d. 151. Avisos de Diego de Mallorca, Nápoles 1577.

87. AGS, Estado, Costas de África y Levante, leg. 488, s. d. Consulta para Su Majestad, Aranjuez 10 de mayo 1577. 
El capitán tenía una biografía muy particular. Originario de Epiro, Combi había combatido en el ejército veneciano durante la guerra de Chipre. ${ }^{88}$ Cautivado entonces por los turcos, un mercader griego se había interesado por su caso, rescatándolo de los baños otomanos. Pero las autoridades de Constantinopla desconfiaban de sus tramas, así que el levantino fue encarcelado y torturado. Durante los suplicios Jerónimo mostró una gran resistencia y fidelidad, consiguiendo así ganar la confianza de Hasan Agá, que estuvo presente durante los tormentos por ser secretario del Gran Visir:

Il quale suo Segretario si nomina Asanaga. Il quale havendo visto gli travagli, gli martirii ch'io haveva schoso, et havendo lui visto la resistenzza haveva fatto neli tormenti et promese che mi fevano, se scopresse il negotio, et non potendo cavar cosa alcuna da me, et sapendo lui apreso pocho ch'io era al servigio de Vostra Maestà, secretamente me ha favorito a tal che per messo de favori suoi et a diversi altri amici, tutti servi de Vostra Maestà, mi sonno liberato ${ }^{89}$.

En aquel momento Jerónimo Combi se proclamaba albanés, esta decisión estaba determinada sobre todo por el escepticismo de la corte hispana hacia los griegos ${ }^{90}$. Pero su trayectoria como espía de la Corona duró muchas décadas. En pocos años Combi se convertiría en la principal referencia de los exiliados helenos en la capital napolitana, tanto que en la iglesia ortodoxa de Nápoles se construyó una lápida en su memoria, aún presente.

Il continuo stimulo tengo ogni giorno dalla Grecia, da diferente parte e particolarmente dale provinzie di Macedonia, Epiro et altre. Circonviene quelle che mandarono li loro ambasciatori li anni passati alla Maestà Vostra, lo quali como so uno dela medesima natione, e como sanno che sono creato della Maestà Vostra et del Conte de Lemos che sia in el ciel lo anno passato in nome della Maestà Vostra me mando in queste parte di Grecia. Per vedere et intendere il fondamento, che tiene questo negotio et la volontà deli populi, et in particulare dei primari ${ }^{91}$.

El primer acercamiento de Combi a la Monarquía Hispánica estaba testificado por la carta que en abril de 1577 escribió a Antonio Pérez, secretario de Felipe II. El espía levantino repetía la convicción de Hasan Agá. Los planteamientos del renegado iban a ser el mejor instrumento para que Jerónimo entrase de forma orgánica en la red de espionaje de Su Majestad.

88. La primera parte de su vida en Floristán ImízCOZ, J. M.: Fuentes para la política oriental de los Austrias. La documentación Griega del Archivo de Simancas, León, 1988.

89. AGS, Estado, Costas de África y Levante, leg. 487, s. d. Jerónimo Combi a Antonio Pérez, Argel 20 abril 1577.

90. Bunes Ibarra, M. Á.: «La conquista turca de Bizancio según los cronistas europeos de los siglos XVI y XVII», Erytheia, 13, 1992, pp. 89-102.

91. AGS, Estado, Nápoles, leg. 1098, d. 116. Jerónimo Combi a Felipe III, Nápoles 26 julio 1602. 
El espía había estado en la capital napolitana, donde se había entrevistado con Giovanni María Renzo, quien le encomendó un despacho para el rey, gracias al cual Combi llevaba todavía más referencias sobre su fidelidad a la Corona:

Vostra Maestà potrà vedere dalle fede, et patente che porta Jerónimo Combi, quanto fidelmente ha servito á Constantinopoli la Vostra Maestà, non ho già voluto mancare de aconpagniarlo con questa mia, con la qual' umilmente supplico la Maestà Vostra de haverlo per recomendato, mettendo consideratione alli serviti fatti, alli pericoli corsi, et ha molti tormenti patitti, et diversi dinari spesi per sarvarsi la vita ${ }^{92}$.

Tras la parada en Nápoles Jerónimo Combi estuvo en Argel, así que su camino hacia la corte revelaba la posibilidad de que el levantino estuviese metido de alguna forma en la negociación más importante del momento: el pasaje del Bey de Argel, Mehemet, al servicio de la Casa de Austria. Contemporáneamente al viaje de Combi a la corte, Bartolomé Bruti de hecho llevaba una carta del corsario para Felipe II $^{93}$ :

Molte volte con mia grandissima allegrezza ho sentito raggionar Bartholomeo Bruti homo mio molto fidatissimo della grandezza et generosita di Vostra Maestà in esser sempre prontissimo di abrazzar, et favorir tutti quelli, che a Sua Maestà ricorreno di aiuti giustissimi et discorrendo col sopradetto circa gli regni di Barberia, ho deliberato con la prima occasione di voler intrar nella gratia et amicitia di Vostra Maestà si come per sue persussioni son intrato et spero che da questo principio risulterà bon fine così alli mei posteri, come alli regni vicini a Vostra Maestà ${ }^{94}$.

Poco después de la carta a Antonio Pérez, las propuestas de Combi fueron examinadas en una reunión del Consejo de Estado. En la junta los mandatarios debatieron en torno a varios asuntos relacionados con Constantinopla. El mayor interés estaba dedicado al caso de Mehemet Bey, que gestionaba Bartolomé Bruti. Conocidas las proposiciones de Combi, el albanés pidió expresamente a Felipe II que durante un tiempo no hubiese movimientos de espías en la capital turca. Bruti temía a los otros agentes, que con sus hazañas podían obstaculizar el asunto con el Bey de Argel.

Junto a Combi llegó a la península ibérica Nicolo Griego, que tenía nexos con los confidentes más antiguos de Constantinopla. El heleno, de hecho, había prestado trescientos ducados a Aurelio Santa Croce para la boda de su hija, y ahora quería la devolución del dinero por parte de la corte.

92. AGS, Estado, Nápoles, leg. 1073, d. 21. Giovanni María Renzo a Felipe II, Nápoles 29 enero 1577.

93. Sola Castaño, E. y de la Peña, J. F.: Cervantes y la Barbería, Madrid, 1996.

94. AGS, Estado, Costas de África y Levante, leg. 487, s. d. Mehemet Bey a Felipe II, Constantinopla 21 julio 1576. 
Finalmente Jerónimo Combi aseguraba a los nobles del consejo que gracias a su amistad dos caudillos levantinos, ahora vasallos de la República de Venecia, pasarían al servicio de Felipe II. Además, una nueva revuelta de los chimariotas había explotado contra los cuarteles de los turcos. Pero el rey no pensaba necesario que se aumentasen los gastos, arriesgando un peligroso inconveniente con los venecianos:

Ofrece el dicho Combi de reducir al servicio de Su Majestad dos caballeros albaneses, el uno pariente suyo capitán de 300 caballos, que está en servicio de Venecianos en la guardia de Corfú. Y el otro que se llama Dulí, que es cabeza de cinco bajeles que residen en algunos casales cerca de Corfú. [Al margen, letra del rey] No sé qué necesidad hay agora desto, y así será mejor escusarlo ${ }^{95}$.

Las decisiones de Felipe II fueron avaladas cinco días más tarde, Bruti tenía que ir lo antes posible hacia Levante para concluir su misión, mientras que Jerónimo Combi y Nicolo Griego se ponían a disposición del Virrey de Nápoles, además los dos serían pagados por la secretaria virreinal:

En lo que toca al Combi, entendiéndose como se entiende que es hombre de servicio, y habiendo, por otra parte, la consideración que vuestra majestad advierte, que es mejor que estos no se entretengan aquí por si alguno fuese espía, se le podrían dar 12 escudos de entretenimiento, advirtiendo al Virrey de Nápoles que, conforme a lo que sirviere y mereciere, así se los continú $e^{96}$.

En julio de 1577 el rey escribió otra vez a Diego de Mallorca. En la carta, Felipe II agradecía tanto los riesgos asumidos por Combi como las tareas de Hasan Agá, al cual Su Majestad prometía amparo y protección en algunos de sus reinos, si el renegado se hubiese encontrado en dificultad:

Os lo agradezco y encargo que de lo que más entendiéredes tengáis cuidado de avisarme, y a vuestro primo le daréis de mi parte las gracias, animándole que lleve adelante el buen propósito que muestra tener. Y certificándole que siempre que él se quisiere recoger en alguno de mis Reinos, con hacer algún servicio señalado a nuestro señor y a mí, será en ellos acogido y admitida su persona, y todo lo que consigo trujese. Y se le hará el buen tratamiento que es razón ${ }^{97}$.

El mismo día el monarca explicaba en una misiva al Virrey de Nápoles, Marqués de Mondéjar, los avances de los negocios relacionados con el fraile, además de

95. AGS, Estado, Costas de África y Levante, leg. 488, s. d. Consulta para Su Majestad, Aranjuez 10 mayo 1577.

96. AGS, Estado, Nápoles, leg. 1074, d. 150. Órdenes de Felipe II, 15 mayo 1577. 1577.

97. AGS, Estado, Nápoles, leg. 1074, d. 160. Felipe II a Diego de Mallorca, San Lorenzo 12 julio 
recordar el primer y dramático encuentro entre Combi y Hasan Agá. En fin, Felipe II mandaba a su representante que diese licencia a Diego de Mallorca para irse a Constantinopla, donde el monje no tenía nada que temer, porque lo iban a proteger sus cofrades residentes en la capital otomana:

Si se le enviaba a Constantinopla un fraile primo hermano suyo, de la orden de san Francisco, que se llama fray Diego de Mallorca (donde diz que podrá estar con seguridad, como están otros frailes) avisaría por su medio el dicho Sanaga de todas las cosas que él supiese de los andamientos y resoluciones del Turco. Y porque el dicho fraile estuvo aquí los meses pasados y refirió esto mismo, y hallándose agora en ese Reino, os he querido avisar dello para que lo tengáis entendido ${ }^{98}$.

Después el rey establecía en otras epístolas para el virrey que se concediesen en el Reino de Nápoles las mercedes para Jerónimo Combi y Nicolo Griego. Al primero se le daban doce escudos al mes más una ayuda de otros doscientos para los recientes gastos de viaje, sin embargo, el beneficio de Nicolo Griego oscilaba entre los cuatro y los seis escudos mensuales ${ }^{99}$. El último cometido de Felipe II para el Marqués Mondéjar era el pago del préstamo hecho por el heleno a Aurelio Santa Croce, que el virrey tenía que devolver al espía ${ }^{100}$. ¡Por fin la nueva red de Estambul estaba lista!

\section{BibLIOGRAFÍA}

Alberi, E.: Relazioni degli ambasciatori veneti al Senato. Florencia, 1840, serie III, volumen I.

Alonso Acero, B.: «Heterodoxia e Inquisición en las sociedades hispanas de Berbería, siglos XVI-XVII», Hispania sacra, 55/112, 2003, pp. 481-500. <http://dx.doi.org/10.3989/ hs.2003.v55.i112.155>.

Aubin, J.: «Une frontière face au péril ottoman: la Terre d'Otrante (1529-1532)», en Veinstein, G.: Soliman le Magnifique, et son temps. París, 1992, pp. 465-484.

Bennassar, B.: Don Juan de Austria. Un héroe para un imperio. Madrid, 2000.

Bouza, F.: Portugal en la monarquía hispánica (1580-1640). Felipe II, las Cortes de Tomar y la génesis del Portugal católico. Madrid, 1987.

Braudel, F.: La Méditerranée et le monde méditerranéen à l'époque de Philippe II. París, 1966.

98. AGS, Estado, Nápoles, leg. 1074, d. 161. Felipe II al Marqués de Mondéjar, San Lorenzo 12 julio 1577.

99. AGS, Estado, Nápoles, leg. 1074, d. 191. Felipe II al Marqués de Mondéjar, San Lorenzo 1577; Idem, pp. 193-194. Felipe II al Marqués de Mondéjar, San Lorenzo 1577.

100. AGS, Estado, Nápoles, leg. 1074, d. 195. Felipe II al Marqués de Mondéjar, San Lorenzo 1577. 
Bunes Ibarra, M. Á.: «La conquista turca de Bizancio según los cronistas europeos de los siglos XVI y XVII», Erytheia, 13, 1992, pp. 89-102.

Bunes Ibarra, M. Á. y García Hernán, E.: «La muerte de Don Sebastián de Portugal y el mundo mediterráneo de finales del siglo XVI», Hispania. Revista española de historia, 54/187, 1994, pp. 447-465.

Carnicer García, C. y Marcos Rivas, J.: Espias de Felipe II. Los servicios secretos del Imperio español. Madrid, 2005.

Carnicer García, C. y Marcos Rivas, J.: Espionaje y traición en el reinado de Felipe II: la historia del vallisoletano Martín de Acuña. Valladolid, 2001.

García Arenal, M. y Bunes Ibarra, M. Á.: Los españoles y el Norte de África. Siglos XV-XVIII. Madrid, 1992.

García Hernán, E.: «La conquista y pérdida de Túnez por don Juan de Austria (15731574)», en CANDiAni, G. y Lo Basso, L.: Mutazioni e permanenze nella storia navale del Mediterraneo (sec. XVI-XIX). Milán, 2010, pp. 39-95.

Floristán Imízcoz, J. M.: Fuentes para la política oriental de los Austrias. La documentación Griega del Archivo de Simancas. León, 1988.

González Castrillo, R.: «La pérdida de La Goleta y Túnez en 1574, y otros sucesos de historia otomana, narrados por un testigo presencial Alonso de Salamanca», Anaquel de estudios árabes, 3, 1992, pp. 247-286.

Hess, A. C.: «The Moriscos: An Ottoman Fifth Column in Sixteenth-Century Spain», American Historical Review, 74/1, 1968, pp. 1-25. <http://dx.doi.org/10.2307/1857627>.

Imber, C.: The Ottoman Empire, 1300-1650: the structure of power. Basingstoke, 2002.

Intorcia, G.: Magistrature nel Regno di Napoli. Analisi prosopografica secoli XVI-XVII. Nápoles, 1987.

Kumrular, Ö.: Las relaciones entre el Imperio Otomano y la Monarquía Católica entre los años 1520-1535 y el papel de los estados satélites. Estambul, 2003.

Le Fur, D.: Henri II. París, 2009.

Ochoa Brun, M. Á.: Historia de la diplomacia española. Madrid, 2003, volumen V.

Petta, P.: Despoti d'Epiro e principi di Macedonia. Esuli albanesi nell'Italia del Rinascimento. Lecce, 2000.

Preto, P.: I servizi segreti di Venezia. Milán, 1994.

Rodríguez Salgado, M. J.: Felipe II, el «Paladín de la Cristianidad» y la paz con el Turco. Valladolid, 2004.

Rotнman, E. N.: Brokering Empire: Trans-Imperial Subjects between Venice and Istanbul. Ithaca, 2011.

Sánchez-Molero, J. L. G. y Alonso Acero, B.: "Alá en la corte de un príncipe cristiano: el horizonte musulmán en la formación de Felipe II (1532-1557)», Torre de los Lujanes: Boletín de la Real Sociedad Económica Matritense de Amigos del País, 35, 1998, pp. 109-140.

Sola Cataño, E.: Los que van y vienen. Información y fronteras en el Mediterráneo clásico del siglo XVI. Alcalá de Henares, 2005, pp. 201-250. 
Sola Cataño, E.: Uchali, el calabrés tiñoso o el mito del corsario muladi en la frontera. Barcelona, 2010.

Sola Cataño, E. y De la Peña, J. F.: Cervantes y la Barbería. Madrid, 1996.

Skilliter, S. A.: «The Hispano-Ottoman Armistice of 1581», en C. E. Bosworth: Iran and Islam. Edimburgo, 1971, pp. 491-515.

Tejada Carrasco, C.: «Memoriales de excautivos: una mirada española de Constantinopla tras Lepanto", en Numhauser, P. y Forniés Casals, J. F.: Escrituras Silenciadas. El paesaje como historiografía. Alcalá de Henares, 2013, pp. 381-393.

Turan, E.: «The Marriage of Ibrahim Pasha (ca. 1495-1536). The Rise of Sultan Süleyman's Favorite to the Grand Vizierate and the Politics of the Elites in the Early SixteenthCentury Ottoman Empire», Turcica, 41, 2009, pp. 3-36. <http://dx.doi.org/10.2143/ TURC.41.0.2049287>.

TÜRKÇELIK, E.: «Estambul y las provincias berberiscas en el tránsito de los siglos xvi al XviI», en Bunes Ibarra, M. Á. y Alonso Acero, B.: Orán. Historia de la corte chica. Madrid, 2011, pp. 173-194.

Valensi, L.: Venise et la sublime porte: la naissance du despote. París, 1987. 